\title{
Sexual segregation in ungulates: a comparative test of three hypotheses
}

\author{
K. E. RUGKSTUHL* and P. NEUHAUS \\ University of Cambridge, Dept. of Zoology, LARG, Downing Street, Cambridge, CB2 3EJ, UK
}

(Received 26 March 2001; revised 7 September 2001; accepted 7 September 2001)

\begin{abstract}
In most social ungulate species, males are larger than females and the sexes live in separate groups outside the breeding season. It is important for our understanding of the evolution of sociality to find out why sexual segregation is so widespread not only in ungulates but also in other mammals. Sexual body size dimorphism was proposed as a central factor in the evolution of sexual segregation in ungulates. We tested three hypotheses put forward to explain sexual segregation: the predation-risk, the forage-selection, and the activity budget hypothesis. We included in our analyses ungulate species ranging from non-dimorphic to extremely dimorphic in body size. We observed oryx, zebra, bighorn sheep and ibex in the field and relied on literature data for 31 additional species. The predation-risk hypothesis predicts that females will use relatively predator-safe habitats, while males are predicted to use habitats with higher predation risk but better food quality. Out of 24 studies on different species of ungulates, females and their offspring chose poorer quality but safer habitat in only eight cases. The forage-selection hypothesis predicts that females would select habitat based on food quality, while males should prefer high forage biomass. In fact, females selected higher quality food in only six out of 18 studies where males and females segregated, in eight studies there was no difference in forage quality and in four studies males were in better quality habitat. The activity budget hypothesis predicts that with increasing dimorphism in body size males and females will increasingly differ in the time spent in different activities. Differences in activity budgets would make it difficult for males and females to stay in mixed-sex groups due to increased costs of synchrony to maintain group cohesion. The predictions of the activity budget hypothesis were confirmed in most cases (22 out of 23 studies). The heavier males were compared to females, the more time females spent foraging compared to males. The bigger the dimorphism in body mass, the more males spent time walking compared to females. Lactating females spent more time foraging than did non-lactating females or males. Whether species were mainly bulk or intermediate feeders did not affect sexual differences in time spent foraging. We conclude that sexual differences in activity budgets are most likely driving sexual segregation and that sexual differences in predation risk or forage selection are additive factors.
\end{abstract}

Key words: sexual segregation, predation risk, forage selection, activity budgets, ruminants, ungulates, sociality, social and habitat segregation.

\section{CONTENTS}

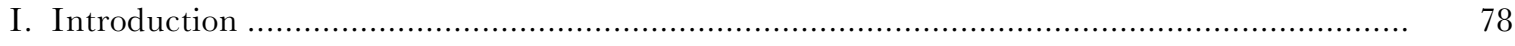

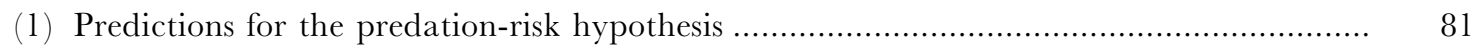

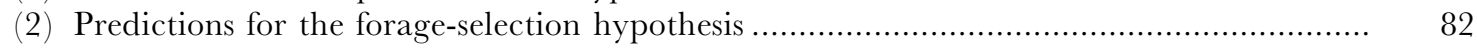

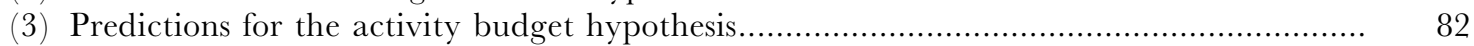

(4) The special case of hindgut fermenters .........................................................

* Corresponding author: K. E. Ruckstuhl, University of Cambridge, Dept. of Zoology, LARG, Downing Street, Cambridge, CB2 3EJ, UK. Tel: (01223) 336643; Fax:(01223) 336676; e-mail: kruckstuhl@hotmail.com 


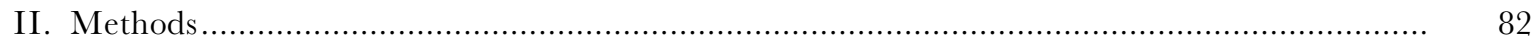

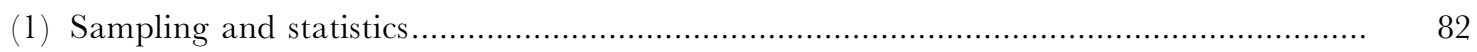

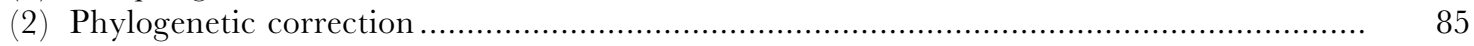

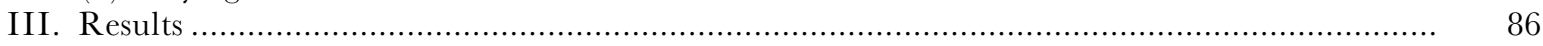

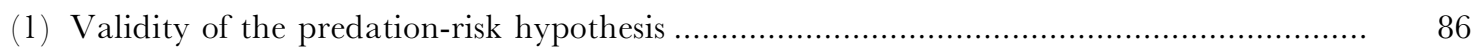

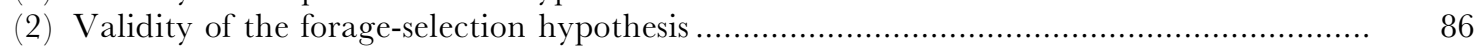

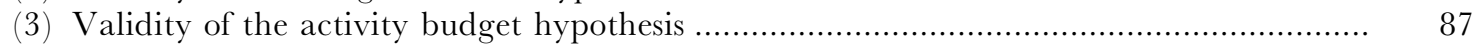

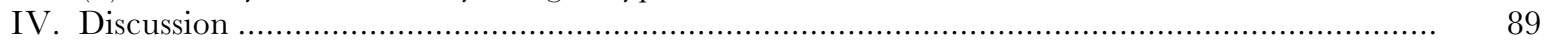

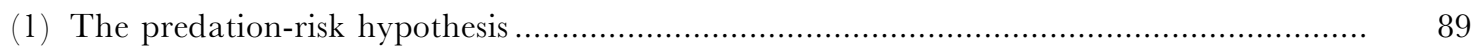

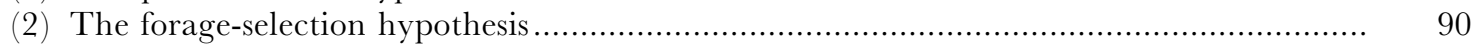

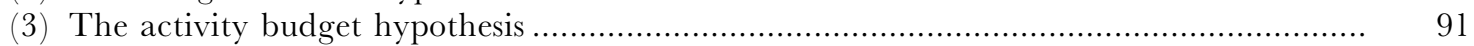

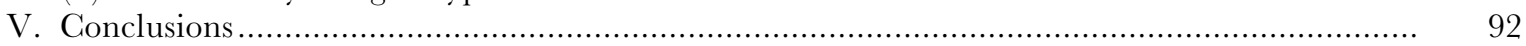

(1) A new model to explain sexual segregation ........................................................... 92

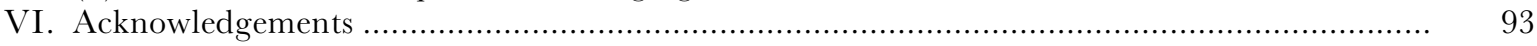

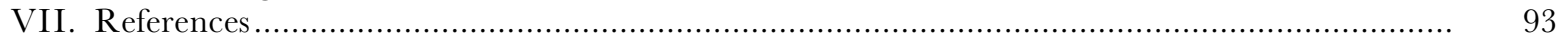

\section{INTRODUGTION}

Sexual segregation is widespread among social mammals. In most ungulate species, males and females live in separate groups (social segregation) outside the breeding season. In addition, the sexes sometimes prefer different habitat types, leading to segregation by habitat (Clutton-Brock, Guinness \& Albon, 1982). To understand the evolution of sociality we need to investigate what factors cause this segregation by sex.

Of the many hypotheses proposed to explain sexual segregation (Main \& Coblentz, 1990; Main, Weckerly \& Bleich, 1996; Miquelle, Peek \& Van Ballenberghe, 1992; Ruckstuhl \& Neuhaus, 2000), three have emerged as most promising: the reproductive strategy hypothesis (predation-risk hypothesis), the sexual dimorphism-body-size hypothesis (forage-selection hypothesis), and the body-size predation hypothesis (activity budget hypothesis). We will be using the Ruckstuhl \& Neuhaus (2000) denominations given in parentheses above to refer to the different hypotheses below as they relate directly to the cause hypothesised to drive sexual segregation. While the predation-risk and the forage-selection hypothesis have tried to explain segregation through sex differences in habitat choice, the activity budget hypothesis attempts to explain social segregation in general. It has been assumed that social segregation is mainly driven by habitat segregation, however, Conradt (1999) clearly showed that social segregation in red deer (Cervus elaphus) and Soay sheep (Ovis aries) is independent of habitat segregation and is therefore not a by-product of habitat segregation but a separate phenomenon. We thus treat social and habitat segregation as different types of sexual segregation. The main assumptions and key pre- dictions of each hypothesis are listed in Table 1 [see Main \& Coblentz (1990); Main et al. (1996); Miquelle et al. (1992); Ruckstuhl \& Neuhaus (2000) for detailed reviews of hypotheses]. All these hypotheses were formulated for sexually dimorphic species where males are bigger than females.

To understand the origin of sexual segregation (both social and habitat segregation) and to detect the factors affecting it, it is of a paramount importance to test the different hypotheses and to perform comparative analyses on a range of ungulate species differing in sexual body size dimorphisms. While this procedure could be a key to solve the enigma of sexual segregation, different factors proposed to affect sexual segregation have never been tested in a comparative analysis of species with varying degrees of sexual size dimorphism.

The predation-risk, forage-selection and activity budget hypotheses have so far been studied only on a single ungulate species at a time (Bleich, Bowyer \& Wehausen, 1997; Gross, 1998; Main, 1998; Main et al., 1996). However, Main (1998) rightly pointed out that seeking species-specific explanations for sexual segregation is unlikely to further our understanding of sexual segregation in general. Different studies to test the same hypothesis often lead to contrary results, as for example for the forageselection hypothesis. Some studies found that males were feeding on the same quality or even better quality forage than females, while others found that females were using higher quality forage as predicted (Bleich et al., 1997; Bowyer, 1984; Main \& Coblentz, 1996; Cransac et al., 1998; Cransac \& Hewison, 1997; du Toit, 1995; Frid, 1999; Koga \& Ono, 1994; Ruckstuhl, 1998). Although the predationrisk hypothesis (originally coined by Main \& Coblentz, 1996) has been supported by a number of 
Table 1. Summary of assumptions and key predictions of three hypotheses advanced to explain sexual segregation in ungulates

\begin{tabular}{|c|c|c|c|}
\hline Hypothesis & Main assumptions & Key predictions & References \\
\hline Predation-risk & $\begin{array}{l}\text { (1) Females and especially offspring } \\
\text { are more vulnerable to predation } \\
\text { than the larger males } \\
\text { (2) Males need food of high quality to } \\
\text { be fit competitors during the } \\
\text { breeding season }\end{array}$ & $\begin{array}{l}\text { (1) Females with offspring will choose } \\
\text { predator-safe habitats of often } \\
\text { inferior* food quality or quantity } \\
\text { (2) Males will choose habitat with } \\
\text { abundant and high quality food }\end{array}$ & $\begin{array}{l}\text { Bowyer (1984); Jakimchuk et al. (1987); } \\
\text { Main \& Coblentz (1990, 1996); } \\
\text { Main et al. (1996) }\end{array}$ \\
\hline Forage-selection & $\begin{array}{l}\text { (1) Smaller females are less efficient at } \\
\text { forage digestion than the larger } \\
\text { males, due to a small stomach size, } \\
\text { and quicker passage rate of food, } \\
\text { hence food quality is more } \\
\text { important to females than food } \\
\text { quantity. } \\
\text { (2) Males are good at digesting even } \\
\text { low quality food and hence food } \\
\text { quantity is more important for } \\
\text { males than food quality }\end{array}$ & $\begin{array}{l}\text { (2) Males will use lower quality but } \\
\text { higher biomass habitat than females }\end{array}$ & $\begin{array}{l}\text { Beier (1987); Bowyer (1984); } \\
\text { Demment (1982); } \\
\text { McCullough (1979); Short (1963) }\end{array}$ \\
\hline Activity budget & $\begin{array}{l}\text { (2) Big differences in activity budgets } \\
\text { make synchrony of behaviour } \\
\text { difficult and potentially costly }\end{array}$ & $\begin{array}{l}\text { (1) Females will compensate their } \\
\text { lower digestive efficiency by } \\
\text { foraging for longer than males, } \\
\text { while males will spend more time } \\
\text { ruminating or lying than females to } \\
\text { digest forage } \\
\text { (2) Animals with similar activity } \\
\text { budgets will form groups }\end{array}$ & $\begin{array}{l}\text { Conradt (1998); Ruckstuhl (1998, 1999); } \\
\text { Short (1963) }\end{array}$ \\
\hline
\end{tabular}

* Note that the forage-selection hypothesis predicts the opposite outcome to the predation-risk hypothesis, regarding sexual differences in forage selection. While the predation-risk and forage-selection hypotheses predict habitat segregation, the activity budget hypothesis predicts social segregation. 
studies, it also has shortcomings: many ungulate species do not use cover or steep terrain to escape predation, but rather form large groups as an antipredator strategy, benefiting from group detection and dilution effects (Dehn, 1990). The formation of large groups, however, is not predicted by the predation-risk hypothesis, maybe because large groups would not necessarily lead to segregation.

The activity budget hypothesis proposes that sexually size-dimorphic males and females segregate into different groups due to incompatibilities of activity budgets and movement rates, independent of possible sexual differences in forage selection (Conradt, 1998; Ruckstuhl, 1998, 1999). Dimorphic males and females could well use the same areas (and not segregate by habitat) and select the same plants but they will not forage together due to different activity budgets. According to this hypothesis males and females would then be socially and temporally segregated even when using the same general area. The activity budget hypothesis would fail to explain sexual segregation if males and females showed the same activity patterns but lived segregated or if they differed greatly in their activity budgets but stayed in mixed-sex groups.

Sexual segregation can happen on a seasonal or a year-round basis. While the activity budget hypothesis predicts year-round sexual segregation, the predation-risk and forage-selection hypothesis would only predict seasonal segregation, when the offspring is small and vulnerable or when food quality is diverse. The forage-selection hypothesis, for example, is unlikely to explain sexual segregation in winter in temperate ungulates, or during the dry season in the tropics, when forage quality is similar everywhere.

The aim of the present study is to compare the predictions of the three hypotheses using a wide range of ungulate species, mostly ruminants, varying in sexual size dimorphism.

\section{(1) Predictions for the predation-risk hypothesis}

The predation-risk hypothesis predicts that males and females should segregate whether they are sexually dimorphic or not, because juveniles are smaller than adults, inexperienced and therefore more vulnerable to predation (see assumptions of the predation-risk hypothesis in Table 1). In nondimorphic species, females with dependent offspring are thus expected to use areas with lower predation risk compared to those used by males and nonreproducing females. Non-dimorphic females without young are expected to form mixed-sex groups with adult males.

\section{(2) Predictions for the forage-selection hypothesis}

The forage-selection hypothesis was tested comparing data on food selection in various species. If sexual segregation was present in species where males and females were reported to select similar food items, or males to feed on higher quality food, the forage-selection hypothesis was rejected as an explanation for sexual segregation in that particular study. In non-dimorphic species, however, males and females should select the same quality food except for lactating females. Males and lactating females should therefore segregate and select different quality food at least during early lactation when energy demands for females are at a maximum (Robbins, 1993). It follows that non-lactating females and males of similar-body-sized species should be found in mixed-sex groups.

\section{(3) Predictions for the activity budget hypothesis}

We predicted that increasing body size dimorphism would lead to increasing sexual differences in activity budgets in both non-ruminant and ruminant species. We also predicted that males and females of nondimorphic social species should be found in mixedsex groups year round. It may be argued that males and lactating females only segregate during lactation, when lactating females have a much higher energy requirement than non-lactating females (Robbins, 1993). However, if body-size differences are the driving factor causing sexual segregation non-lactating females and males should also segregate. We therefore predicted that lactating females would spend more time foraging than non-lactating females. This prediction is based on the assumption that lactating females will compensate their higher energy demands by increasing forage intake.

Bunnell \& Gillingham (1985) argued that the time an ungulate spends grazing versus ruminating and digesting per day is affected by the type of forage it consumes: high-quality forage (high in protein, low in fibre) such as leaves or forbs needs less time for rumination and digestion compared to low-quality food such as grass (low in protein, high in fibre). As males of sexually dimorphic ruminant species are 
better at digesting low-quality food than females, due to their larger rumen size (Van Soest, 1994, 1996), females that forage on highly digestible food could compensate their lower digestive efficiency by spending more time foraging. Following this argument we predicted that observed sexual differences in time spent feeding would be greater for intermediate feeders that opportunistically feed on highly digestible forage than for bulk feeding species that predominantly forage on grass [see Hofmann (1989) for a definition of the different feeding types of ruminants].

\section{(4) The special case of hindgut fermenters}

All hypotheses on sexual segregation were formulated for and tested on ruminants because ruminants are more restricted in time allocation to different activities by the constraints of rumination (Demment \& Van Soest, 1985; Van Wieren, 1991). The causes of sexual segregation in hindgut fermenters have been largely ignored. We filled this gap by testing the different predictions for non-ruminants, in particular hindgut fermenters. We expected hindgut fermenters, such as the plains zebra (Equus burchelli), to show smaller sexual differences in activity budgets because digestive capabilities should be similar for males and females, as they do not ruminate. Hindgut fermenters have a higher total intake of forage per unit body mass than ruminants (Duncan et al., 1990) and accordingly spend more time grazing per day. The predictions of the predation-risk hypothesis should be the same as for ruminants because offspring are more vulnerable to predation than adults. According to the forage-selection hypothesis females should select higher quality forage than males in hindgut fermenters due to the increased energy demands of lactation.

For our comparative analyses we relied on literature data on forage selection, predation risk and activity budgets, and observed four key species (plains zebra, oryx Oryx gazella, Rocky Mountain bighorn sheep Ovis canadensis and Alpine ibex Capra ibex) (see Table 2 for a list of the species included).

\section{METHODS}

\section{(1) Sampling and statistics}

We chose to study zebra and oryx because they are sexually non-dimorphic species, while bighorn sheep males are approximately $50 \%$ heavier than females
(Ruckstuhl \& Festa-Bianchet, 2001) and ibex males are more than twice the mass of females (Loison et al., 1999). We set the threshold for non-dimorphic species at a sexual difference in body size of $\leqslant 20 \%$ for ruminants, based on physiological differences in digestion efficiency between species (Van Soest, 1994). Although, there has been some debate on whether a $20 \%$ difference in body mass between males and females of the same species would actually lead to significant differences in time spent in different activities (e.g. grazing or walking) (Hudson \& White, 1985), we assumed that it did affect activity budgets.

Bighorn sheep were observed in the Sheep River Wildlife Sanctuary, Alberta Canada from 19941997 by the first author (Ruckstuhl, 1998). The ibex were studied in the Belledonne-Sept-Laux Reserve, France in June and July 1999, and the oryx and zebra in the Etosha National Park, Namibia, from November 1999 to March 2000. Observations on activity budgets were made using focal animal sampling (Altmann, 1974) on marked (ibex and bighorns) or individually recognisable individuals. All zebra and some oryx were permanently recognisable through coat patterns, scars or shape of horns in oryx, while some oryx were only recognisable for the duration of the observation. Time spent foraging (feeding), walking, standing, or lying was collected by noting transition times from one behaviour to another for individually recognisable focal animals as described by Ruckstuhl (1998). For groups, where not all individuals were recognisable, we used 5 min scan samplings (Altmann, 1974) to evaluate the time spent in different activities for the different age, sex and reproductive classes. Although focal animal sampling and 5 min scan sampling are different techniques they both lead to a good estimate of the proportion of time spent in different activities (Altmann, 1974).

We collected our data during or close to parturition and lactation for ibex and bighorns. Zebra and oryx in the Etosha National Park breed all year round, but most of the offspring in plains zebra seem to be born at the start of or during the rainy season (Estes, 1991). We therefore chose this period for our observations. The literature data often did not refer to the season in which observations were made and did not provide information on the reproductive status of the females. We therefore included all data for general tests of sexual differences in behaviour (simple regressions between sexual differences in body mass and sexual differences in time spent grazing or walking) and then did separate analyses 
Table 2. Female and male body masses of various species of ruminants and hindgut fermenters

Mass difference in $\%=$ percentage difference of male body mass compared to female body mass (see Methods). Mass source $=$ literature source from which body mass was taken. Sexual segregation: $0=$ no segregation, $0.5=$ mixed-groups, temporarily segregated or territorial individuals, $1=$ males and females are segregated outside the breeding season. Dimorphism: $1=$ species with a sexual body mass dimorphism of more than $20 \%, 0=\operatorname{species}$ with less than $20 \%$ sexual dimorphism. Also listed are the tribe names for all ruminants and family names for the hindgut fermenters.

\begin{tabular}{|c|c|c|c|c|c|c|c|c|}
\hline Species & Tribe & $\begin{array}{l}\text { Female body } \\
\text { mass }(\mathrm{kg})\end{array}$ & $\begin{array}{l}\text { Male body } \\
\text { mass }(\mathrm{kg})\end{array}$ & $\begin{array}{l}\text { Mass difference } \\
\text { in } \%\end{array}$ & Mass source & $\begin{array}{l}\text { Sexual } \\
\text { segregation }\end{array}$ & $\begin{array}{l}\text { Dimorphism } \\
>20 \%\end{array}$ & \\
\hline RUMINANTS & & & & & & & & \\
\hline Aepycerus melampus & Aepycerotini & 50 & 62.5 & 25 & Kingdon (1997) & 1 & 1 & \\
\hline Alces alces & Alcini & 500 & 633 & 26.6 & Miquelle et al. (1992) & 1 & 1 & \\
\hline Antilocapra americana & Antilocaprini & 45.4 & 54 & 19 & Weckerly (1998) & 0 & 0 & \\
\hline Bison bison athabascae & Bovini & 425 & 700 & 64.7 & Weckerly (1998) & 1 & 1 & \\
\hline Capra ibex & Caprini & 45 & 95 & 111 & Loison et al. (1999) & 1 & 1 & \\
\hline Capreolus capreolus & Capreolini & 23 & 24.75 & 8 & Weckerly (1998) & 0.5 & 0 & \\
\hline Cervus elaphus & Cervini & 255 & 340 & 33 & Weckerly (1998) & 1 & 1 & \\
\hline Cervus nippon nippon & Cervini & 40 & 55 & 37.5 & Koga \& Ono (1994) & 1 & 1 & \\
\hline Connochaetes gnou & Alcelaphini & 200 & 227.5 & 14 & Kingdon (1997) & 0.5 & 0 & \\
\hline Connochaetes taurinus & Alcelaphini & 193 & 231 & 19.69 & Owen-Smith (1988) & 0.5 & 0 & \\
\hline Damaliscus dorcas & Alcelaphini & 56 & 74 & 32 & Estes (1974) & 1 & 1 & \\
\hline Gazella thomsoni & Antilopini & 18.5 & 22 & 19 & Owen-Smith (1988) & 0.5 & 0 & \\
\hline Giraffa camelopardalis & Giraffini & 800 & 1200 & 50 & Owen-Smith (1988) & 1 & 1 & \\
\hline Kobus ellipsiprymnus & Reduncini & 180 & 250 & 39 & Kingdon (1997) & 1 & 1 & \\
\hline Litocranius walleri & Antilopini & 31 & 45 & 45 & Estes (1974) & 1 & 1 & \\
\hline Madoqua kirkii & Antilopini & 5.3 & 5.2 & -2 & Owen-Smith (1988) & 0 & 0 & \\
\hline Odocoileus hemionus & Odocoilini & 68.5 & 93 & 35.77 & Weckerly (1998) & 1 & 1 & \\
\hline Odocoileus virginianus & Odocoilini & 49.5 & 82 & 65.66 & Weckerly (1998) & 1 & 1 & \\
\hline Oreotragus oreotragus & Neotragini & 13 & 11 & -15.39 & Owen-Smith (1988) & 0 & 0 & $\bar{X}$ \\
\hline Oryx gazella & Hippotragini & 202.5 & 210 & 4 & Kingdon (1997) & 0 & 0 & $i$ \\
\hline Ovibos moschatus & Ovibovini & 188 & 277 & 47 & Weckerly (1998) & 1 & 1 & \\
\hline Ovis aries (Soay sheep) & Caprini & 25 & 35 & 40 & Owen-Smith (1988) & 1 & 1 & 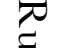 \\
\hline Ovis canadensis & Caprini & 71 & 106 & 49 & $\begin{array}{l}\text { Ruckstuhl \& Festa- } \\
\text { Bianchet }\end{array}$ & 1 & 1 & $\overline{0}$ \\
\hline Ovis dalli dalli & Caprini & 48.8 & 76.6 & 57 & Weckerly (1998) & 1 & 1 & 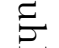 \\
\hline Ovis musimon & Caprini & 44.9 & 67.9 & 51 & $\begin{array}{l}\text { Pérez-Barberia \& } \\
\text { Gordon }(2000)\end{array}$ & 1 & 1 & Еี \\
\hline Rangifer tarandus & Rangiferini & 71 & 103 & 45 & Weckerly (1998) & 1 & 1 & 2 \\
\hline Rupicapra pyrenaica parva & Rupicaprini & 23.5 & 30.5 & 30 & Pérez-Barberia et al. (1997) & 1 & 1 & \\
\hline Syncerus cafer & Bovini & 576 & 686 & 19 & Estes $(1974)$ & 0.5 & 0 & 2 \\
\hline Tragelaphus spekei selousi & Tragelaphini & 53 & 100 & 89 & Weckerly (1998) & 1 & 1 & $\stackrel{2}{2}$ \\
\hline Tragelaphus strepsiceros & Tragelaphini & 170 & 257 & 51 & Owen-Smith (1988) & 1 & 1 & 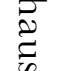 \\
\hline
\end{tabular}




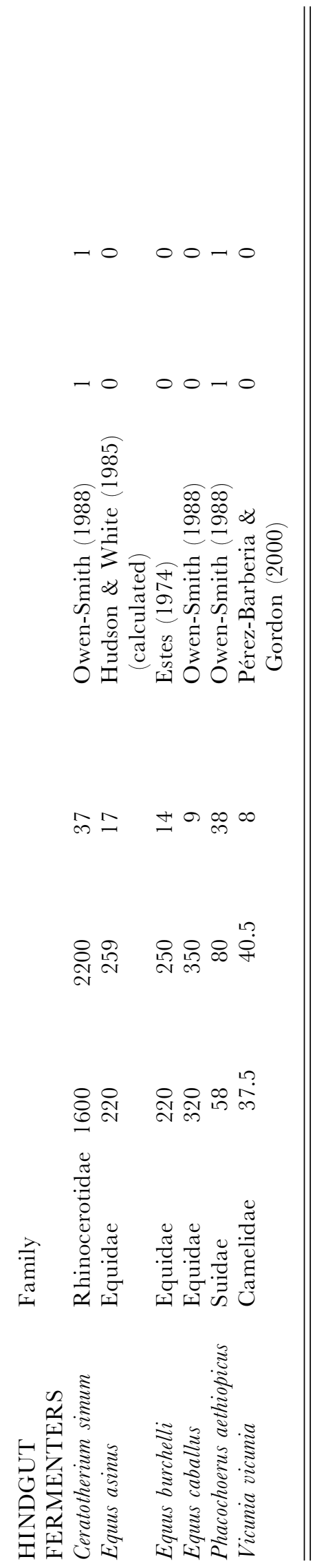

with respect to reproductive status of known females using General Linear Models (GLMs).

As zebras and oryx both live in mixed-sex groups, habitat choice and predation risk are always the same for both sexes within a group, but may differ between groups. Indeed, we found both zebra and oryx in various types of habitat such as on open plains, the Etosha salt pan, and in bushy as well as in forested areas. We searched all types of habitats equally. For each group we noted the habitat type our study animals were using (open, bushy or forested). Lions (Panthera leo), the main predator of zebra and oryx, use both bushy and open habitats (Estes, 1991). For literature data analyses we considered steep cliffs, inaccessible areas or bush for concealment of young as relatively predator-safe areas compared to flat open ground or hills. For all studies on species where data on predation risk were lacking we looked for studies on the same species where habitat use was mentioned and we could infer sexual differences in safety from predation. Studies, where no such data could be found were excluded from the analysis on predation risk.

Forage selection was assessed by analysing the quality (faecal crude protein content) of forage consumed by bighorn sheep (Ruckstuhl, 1998), and by noting the preference for bushes versus grasses and herbs for ibex (P. Neuhaus \& K. E. Ruckstuhl, in preparation), oryx and zebra. As zebra and oryx lived in mixed-sex groups we did not analyse sexual differences in diet selection as they used the same area at the same time - any difference in diet selection would obviously not have led to sexual segregation. We compared the literature data qualitatively, as we did not have the same measurements and methods to assess sexual differences in forage selection for all studies. If females of sexually dimorphic species ( $>20 \%$ difference in body mass) were reported to consume higher quality forage or select higher quality habitat than males, then the forage-selection hypothesis was judged as supported by that particular study. Studies with no information on forage selection or quality were excluded from the analysis on sexual differences in forage selection.

Data on body mass were collected from the literature (Table 2). Taking the females body mass as $100 \%$, we calculated sexual dimorphism as follows:

$$
S D B M=(M W * 100 / F W)-100 \%,
$$

where $S D B M=$ sexual difference in body mass, $M W=$ male mass, and $F W=$ female mass. The per 
Table 3. Studies providing data on sexual differences in forage selection, predation risk or activity budgets $\mathrm{pr}=$ predation risk, $\mathrm{m}=\mathrm{f}$ there is no difference in predation risk, $\mathrm{m}>\mathrm{f}=$ males are in riskier habitat than females, $\mathrm{m}<\mathrm{f}=$ females are in riskier habitat than males, $<>$ means that both outcomes have been observed. PRH $=$ support for the predation-risk hypothesis. Food quality: $\mathrm{m}>\mathrm{f}=$ food in male habitat is better than in female habitat, $=$ same quality, $\mathrm{m}<\mathrm{f}=$ females are in better quality habitat. FSH $=$ whether yes or no the forageselection hypothesis was supported by the study. Graze $(\%)=$ the sexual difference in $\%$ time spent grazing (see Methods), ABH = whether or not the activity budget hypothesis was supported.

\begin{tabular}{|c|c|c|c|c|c|c|c|c|c|}
\hline Species & pr & Reference & PRH & Food quality & Reference & FSH & graze $(\%)$ & Reference & $\mathrm{ABH}$ \\
\hline \multicolumn{10}{|l|}{ RUMINANTS } \\
\hline Aepycerus melampus & $m>f$ & Mysterud (2000) & yes & $\mathrm{m}<\mathrm{f}$ & Mysterud (2000) & yes & 5.49 & Bunnell \& Gillingham (1985) & no \\
\hline Alces alces & $m>f$ & Miquelle $e t$ al. (1992) & yes & $m=f$ & Miquelle et al. (1992) & no & & & \\
\hline Antilocapra americana & $m=f$ & Byers (1997) & no & $m=f$ & Byers (1997) & no & 18.30 & Byers (1997) & yes \\
\hline Bison bison athabascae & $m=f$ & Larter \& Gates (1991) & no & $m=f$ & Larter \& Gates (1991) & no & & & \\
\hline Capra ibex & $m>f$ & Villaret et al. (1997) & yes & $\mathrm{m}<\mathrm{f}$ & $\begin{array}{l}\text { P. Neuhaus \& K. E. Ruckstuhl } \\
\text { (in preparation) }\end{array}$ & yes & 72.73 & P. Neuhaus \& K. E. Ruckstuhl (in preparation) & yes \\
\hline Capreolus capreolus & $m=f$ & Mysterud (2000) & no & $\mathrm{m}<\mathrm{f}$ & Mysterud (2000) & yes & -7.46 & Bunnell \& Gillingham (1985) & yes \\
\hline Cervus elaphus & & & & $\mathrm{m}<>\mathrm{f}$ & Clutton-Brock et al. (1982) & no & 11.63 & Clutton-Brock et al. (1982) & yes \\
\hline Cervus nippon nippon & . & & & $m>f$ & Koga \& Ono $(1994)$ & no & & & \\
\hline Connochaetes gnou & & & & & & & -6.70 & Vrahimis \& Kok (1993) & yes \\
\hline Connochaetes taurinus & & & & & & & 11.11 & Berry $(1980)$ & \\
\hline Damaliscus dorcas & $m=f$ & Estes (1991) & no & & & & 15.39 & Estes (1991) & yes \\
\hline Gazella thomsoni & $m=f$ & Estes (1991) & no & $m \leqslant f$ & Estes (1991) & no & 15.28 & Walther (1973) & yes \\
\hline Giraffa camelopardalis & $m>f$ & Ginnett \& Demment $(1997)$ & yes & $\mathrm{m}<\mathrm{f}$ & Pellew (1984) & yes & 23.29 & Ginnett \& Demment (1997) & yes \\
\hline Kobus ellipsiprymnus & $m<f$ & Estes (1991) & yes & $m=f$ & Mysterud (2000) & no & 35.23 & Spinage (1968) & yes \\
\hline Litocranius walleri & & & & & & & 22.06 & Leuthold \& Leuthold (1978) & yes \\
\hline Madoqua kirkii & $m=f$ & Estes (1991) & no & $m=f$ & Manser \& Brotherton (1995) & no & 20.00 & Manser \& Brotherton (1995) & yes \\
\hline \multirow[t]{2}{*}{ Odocoileus hemionus } & $\mathrm{m}<>\mathrm{f}$ & Bowyer (1984) & no & $m=f$ & Bowyer (1984) & no & & & \\
\hline & $m>f$ & Main \& Coblentz (1996) & yes & $m>f$ & Main \& Coblentz (1996) & no & & & \\
\hline Odocoileus virginianus & & & & $m<f$ & Beier (1987) & yes & & & \\
\hline Oreotragus oreotragus & $m=f$ & Estes (1991) & no & $m=f$ & Estes (1991) & no & 25.30 & Dunbar (1979) & yes \\
\hline Oryx gazella & $m=f$ & Present study & no & $m=f$ & Present study & no & -14.00 & Present study & yes \\
\hline Ovibos moschatus & & & & & & & 37.14 & Oakes et al. (1992) & yes \\
\hline Ovis aries (Soay sheep) & & & & $m=f$ & Pérez-Barberia \& Gordon (1999) & no & 7.50 & Bunnell \& Gillingham (1985) & yes \\
\hline Ovis canadensis & $m>f$ & Bleich et al. (1997) & yes & $\mathrm{m}=\mathrm{f}$ & Ruckstuhl (1998) & no & 26.66 & Ruckstuhl (1998) & yes \\
\hline Ovis dalli dalli & $m>f$ & Rachlow \& Bowyer (1998) & no & $m=f$ & Seip \& Bunnell (1985) & no & 12.32 & Bunnell \& Gillingham (1985) & yes \\
\hline Ovis musimon & & & & $m=f$ & Cransac \& Hewison (1997) & no & 11.39 & Moncorps et al. (1997) & yes \\
\hline Rangifer tarandus & $m>f$ & Jakimchuk et al. (1987) & yes & $m>f$ & Jakimchuk et al. (1987) & no & & & \\
\hline Rupicapra pyrenaica parva & & & & $m<f$ & Pérez-Barberia et al. (1997) & yes & 24.10 & Pérez-Barberia et al. (1997) & yes \\
\hline Syncerus cafer & $m>f$ & Prins \& Iason (1989) & no & $\mathrm{m}=\mathrm{f}$ & Prins \& Iason (1989) & no & 18.32 & Prins (1996) & yes \\
\hline Tragelaphus spekei selousi & $m=f$ & Estes $(1991)$ & no & & & & 55.85 & Games (1983) & yes \\
\hline Tragelaphus strepsiceros & & & & & & & 14.74 & Owen-Smith $\quad 1998\rangle$ & yes \\
\hline HINDGUT FERMENTERS & & & & & & & & & \\
\hline Ceratotherium simum & & & & & & & 13.36 & Owen-Smith (1988) & yes \\
\hline Equus asinus & $m=f$ & Estes (1991) & no & & & & 26.36 & Bunnell \& Gillingham (1985) & yes \\
\hline Equus burchelli & $m=f$ & Estes (1991) & no & $m=f$ & Present study & & 3.02 & Present study & yes \\
\hline Equus caballus & $m=f$ & Estes (1991) & no & $\mathrm{m}=\mathrm{f}$ & Lenarz (1985) & & 8.91 & Duncan $(1980)$ & yes \\
\hline Phacochoerus aethiopicus & & & & & & & 42.69 & Cough \& Hassam (1970) & yes \\
\hline Vicunia vicunia & & & & & & & 19.22 & Bosch \& Svensen (1987) & yes \\
\hline
\end{tabular}




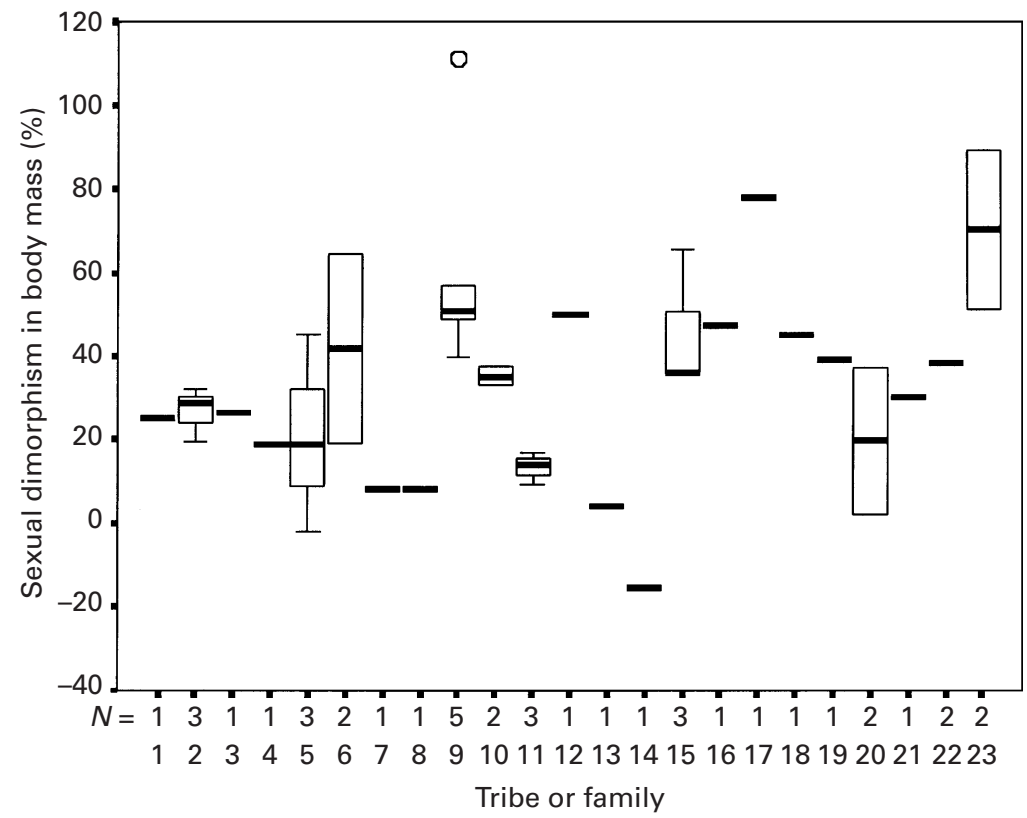

Fig. 1. The distribution of sexual size dimorphism over the different tribes or families and the number $(\mathcal{N})$ of species studied within each. Tribes of families $1=$ Aepycerotini, $2=$ Alcelaphini, $3=$ Alcini, $4=$ Antilocaprini, $5=$ Antilopini, 6 = Bovini, $7=$ Camelidae, $8=$ Capreolini, $9=$ Caprini, $10=$ Cervini, $11=$ Equidae, $12=$ Giraffini, $13=$ Hippotragini, $14=$ Neotragini, $15=$ Odocoilini, $16=$ Ovibovini, $17=$ Probiscini, $18=$ Rangiferini, $19=$ Reduncini, $20=$ Rhinocerotini, $21=$ Rupicaprini, $22=$ Suidae, $23=$ Tragelaphini. The single circle represents the extreme sexual dimorphism found in Alpine ibex, which was also included in the analysis. Box plots represent minima, maxima, median (bold horizontal lines) and interquartile ranges (boxes).

cent males and females differed in time spent feeding or walking was calculated as:

$$
S D A B=100 \%-(M A * 100 / \% F A),
$$

where $S D A B=$ sexual difference in activity budgets, $M A=\%$ time male was active (feeding or walking), and $F A=\%$ time female was active.

Per cent data were arcsine-square-root transformed to meet assumptions of normality (Sokal \& Rohlf, 1995). The effects of body size differences on time spent foraging or walking were tested using simple regressions. Effects of feeding styles (bulk, intermediate feeders and browsers) and digestion type (ruminant versus hindgut fermenters) on time spent feeding were analysed using GLMs. We also tested how sexual dimorphisms in body mass and differences in time spent foraging potentially affected sexual segregation by using ordinal logistic regressions (segregation values were either 0 for no segregation, 0.5 for cases where there are mixed-sex as well as segregated groups, and 1 for strictly sexually segregated groups; Table 2 ).

To evaluate the validity of the predation-risk, the forage-selection and the activity budget hypothesis we used binomial tests (for each of the three hypotheses separately). The binomial test tells us if the results go significantly in the direction of the prediction of a hypothesis, significantly contrary to the prediction or whether there is no discernible trend in any direction. Thus, if the outcome was ambiguous and the predictions were equally supported and not supported, the hypothesis was rejected as an explanation for sexual segregation. The hypothesis was also rejected when the data were consistently contrary to the predictions. To decide whether predictions were supported or not supported, we determined for each study whether or not the results met the predictions of a particular hypothesis (Table 3 ).

\section{(2) Phylogenetic correction}

Several authors recommend phylogenetic corrections when performing comparative analyses, because some species share the same phylogenetic history and traits may therefore be correlated (Felsenstein, 1985; Harvey \& Mace, 1982; Harvey \& Pagel, 1998; Harvey, Read \& Nee, 1995; Pagel, 1992). However, other scientists have debated the usefulness of phylogenetic corrections (Rees, 1995; Westoby, Leishman \& Lord, $1995 a, b)$. No complete phylogeny exists for our data set, or for the order Artiodactyla. Furthermore, recent arguments 
(Harvey \& Rambaut, 2000) have questioned the validity of the independent contrast method for phylogenetic corrections, proposed by Felsenstein (1985).

To account for phylogeny, we separated the different species into the following families: Bovidae, Cervidae, Giraffidae, Camelidae, Suidae, Rhinocerotidae, and Equidae. Most available data were on Bovidae $(\mathcal{N}=19$ species $)$ and Cervidae $(\mathcal{N}=6$ species). However, there was no difference in mean sexual dimorphism between these two families $(F=$ 0.061, $P=0.94$ ) [Bovidae mean \pm standard error of sexual size dimorphism $=41.46 \pm 5.99 \% \quad(95 \%$ confidence interval $(\mathrm{CI})=28.85-54.06 \%$ ), Cervidae mean dimorphism $=42.11 \pm 4.99 \% \quad(\mathrm{CI}=$ $29.28-54.94 \%$ ]. We further separated the different Artiodactyla species into different tribes (Loison et al., 1999), and the hindgut fermenters into families (as there are no tribe names for Perrisodactyla). In Fig. 1, we plotted the different tribes or families against sexual body mass differences. Although there is great variation within tribes, it does not exceed overall variation. On the other hand there is no single tribe with uniform body size dimorphism. We are thus confident that the species and tribes values represent independent data points (Harvey et al., 1995). We further categorised social ruminant species as bulk feeders (grazers), browsers or intermediate feeders (Hofmann, 1989). Average sexual mass dimorphism did not differ between ungulates of the three feeding types $(F=0.33, P=0.72)$ (grazers dimorphism $=38 \pm 5.56 \%, \quad$ CI $=26.81-50.68 \%$, $\mathcal{N}=15$ species; intermediate feeders dimorphism $=$ $46.15 \pm 10.56$, CI $=21.17-71.12 \%, \mathcal{N}=8$ species; browsers dimorphism $=46.66 \pm 1.67 \%, \quad$ CI $=$ $39.49-53.83 \%, \mathcal{N}=3$ ). We thus concluded that sexual differences in body mass or feeding type were not correlated with phylogeny [see also Loison $e t$ al. (1999) on feeding types] and a phylogenetic correction unnecessary (Abouheif, 1999).

\section{RESULTS}

\section{(1) Validity of the predation-risk hypothesis}

Lactating female ibex of our study population were in escape terrain in $100 \%$ of all observations (in June and July 1999), while bachelor groups mainly used grassy slopes ( $75 \%$ of observations) and spent less time in escape terrain ( $25 \%$ of observations). Bighorn sheep females either made more use of escape terrain by spending time in the alpine zone (Festa-Bianchet, 1988) or had much higher move- ment rates than males when sharing the habitat with males (Ruckstuhl, 1998). Overall, females were reported to use safer habitat of inferior quality consistently in only eight out of 20 studies on ruminants (Table 3 ).

Sexual segregation was not as common in nondimorphic species as in dimorphic ones: in 35 studies with data on predation risk, forage selection and activity budgets, sexual segregation was absent in non-dimorphic species and omnipresent in dimorphic species (Table 2). All 13 non-dimorphic ungulates lived in mixed-sex groups or as territorial male-female pairs and hence did not segregate. Oryx stayed in mixed-sex groups, even when females were accompanied by dependent offspring $(77$ mixed-sex groups out of 77 observed groups). Approximately $15 \%$ of plains zebras live in stallion groups and the rest in family groups of one male and several females and their offspring (Lefebre-Smuts, 1974). Although females in some dimorphic species do appear to seek safer habitat than males, the predation-risk hypothesis was not supported as a general explanation of sexual segregation because segregation was confined to dimorphic species, and because only eight studies confirmed the predictions, while 12 studies did not (binomial test: $P=0.503$, Table 3 ). Out of these 12 studies six were on dimorphic species.

\section{(2) Validity of the forage-selection hypothesis}

Among our own study animals there was no sexual difference in the quality (crude protein content) of food selected by bighorn sheep (Ruckstuhl, 1998), despite their large sexual dimorphism, while lactating female ibex fed more on grasses than on bushes compared to males or non-lactating females (P. Neuhaus \& K. E. Ruckstuhl, in preparation), even when using the same habitat. A study on red deer found that females used higher quality forage at one point during the season, whereas males were using better quality forage during another period (Table 3). Sexual segregation was not always associated with sex differences in habitat type or diet: out of 18 studies on different segregating ruminant species, six indeed found females consuming higher quality forage than males, while eight found no sexual difference in forage selection and four found that males consumed higher quality forage than females (Table 3). An additional seven studies on non-dimorphic species, including ruminants and hindgut fermenters, showed no difference in forage selection (Tables 2 and 3 ). 


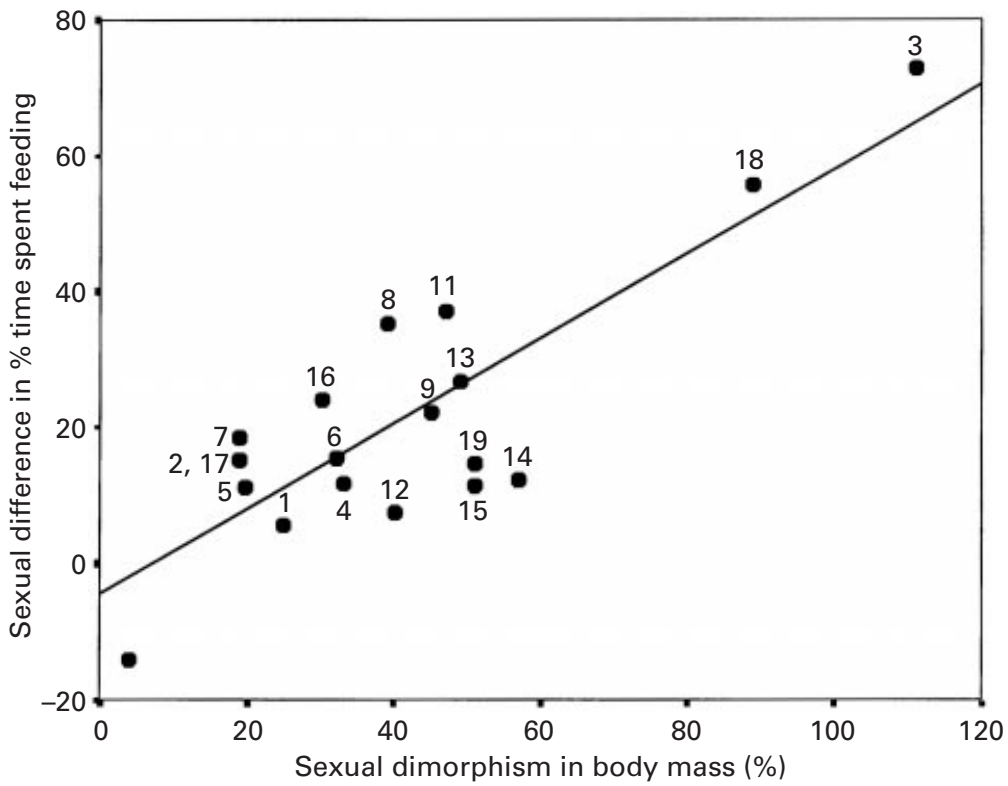

Fig. 2. Relationship between increasing sexual body mass dimorphism (in per cent) and sexual differences in per cent of time spent feeding in social ruminants. Each point represents one species: $1=$ Aepyceros melampus, $2=$ Antilocapra americana, 3 =Capra ibex, $4=$ Cervus elaphus, $5=$ Connochaetes taurinus, $6=$ Damaliscus dorcas, $7=$ Gazella thomsoni, $8=$ Kobus ellipsiprymnus, $9=$ Litocranius walleri, $10=$ Oryx gazella, $11=$ Ovibos moschatus, $12=$ Ovis aries, $13=$ Ovis canadensis, $14=$ Ovis dalli dalli, $15=$ Ovis musimon, $16=$ Rupicapra pyrenaica parva, $17=$ Syncerus cafer, $18=$ Tragelaphus spekei selous $i$, $19=$ Tragelaphus strepsiceros. References to literature sources are given in Table 3.

Oryx and zebra of all reproductive and sex classes formed mixed-sex groups throughout the observation period. They thus had the same quality food available. Overall, we found six studies where females were using habitat with higher quality forage, while 18 other studies found no sexual difference in habitat quality or males in higher quality habitats than females (binomial test: $n_{1}=6$, $n_{2}=18, P=0.023$ ) (Table 3 ). The binomial test is significant in the direction opposite to that expected. The forage-selection hypothesis was therefore rejected as a general explanation of sexual segregation.

\section{(3) Validity of the activity budget hypothesis}

We found a significant difference in time spent grazing between the sexes in ibex (GLM : $F=78.84$, $P<0.001$ ) and bighorn sheep (GLM: $F=16.25$, $P<0.001)$. Ibex females with young $(\mathcal{N}=40)$ spent $30.80 \pm 1.85 \%$ per day grazing, non-lactating females $(\mathcal{N}=5) 19.30 \pm 2.30 \%$, and males $(\mathcal{N}=50)$ $8.41 \pm 1.09 \%$. Female bighorn sheep with young $(\mathcal{N}=87)$ spent $53.91 \pm 1.26 \%$ of their daytime grazing, females without young $(\mathcal{N}=33)$ grazed $42.60 \pm 2.44 \%$ and males $(\mathcal{N}=102) 39.54 \pm$ $0.76 \%$. We did not find a significant difference in time spent grazing in female and male oryx (GLM: $F=0.05, P=0.95)$ or zebra (GLM: $F=0.47$, $P=0.70)$. Oryx females with young $(\mathcal{N}=12)$ spent $17.73 \pm 2.92 \%$, non-lactating females $(\mathcal{N}=23)$ $16.65 \pm 2.84 \%$, and males $(\mathcal{N}=21) 17.74 \pm 2.55 \%$ of their daytime grazing, while in zebras it was $63.25 \pm 4.91 \%$ for lactating females $(\mathcal{N}=14)$, $54.32 \pm 6.86 \%$ for non-lactating females $(\mathcal{N}=10)$ and $63.49 \pm 4.40 \%$ for males $\mathcal{N}=12$ ).

Overall, there was a positive and significant correlation between sexual dimorphism and sexual differences in time spent grazing $\left(r^{2}=0.70\right.$, $P<0.0001, \mathcal{N}=19$, Fig. 2$)$ in social ruminants. As the difference in body mass between males and females increased, females spent more time grazing compared to males. Additionally, differences in time spent grazing were greater between lactating ruminant females and males $\left(n_{1}=8\right.$ male-female regression, $\left.r=0.91, r^{2}=0.84, P<0.01\right)$ than between non-lactating females and males $\left(n_{2}=8\right.$ malefemale regression, $\left.r=0.87, r^{2}=0.76, P<0.01\right)$ (comparison of means: $Z=-2.52, \quad P<0.05$, Fig. 3).

The difference in time spent walking also increased significantly between species as sexual dimorphism increased $\left(r^{2}=0.66, P<0.05, \mathcal{N}=6\right.$ species). Males of most species spent more time walking than the females: oryx males walked for 


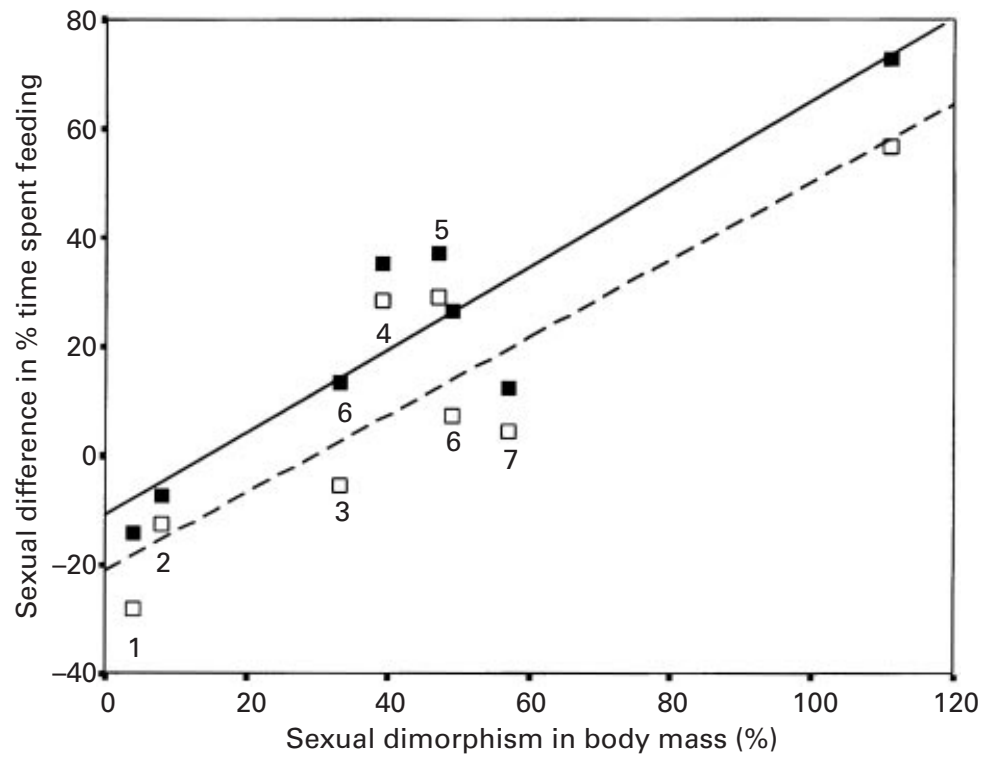

Fig. 3. Relationship between increasing sexual body mass dimorphism and sexual differences in per cent time spent feeding for females with young (filled squares and solid line), compared to females without young (open squares, broken line). Vertical pairs represent the same species: $1=$ Oryx gazella, $2=$ Capreolus capreolus, $3=$ Cervus elaphus, $4=$ Kobus ellipsiprymnus, 5 = Ovibos moschatus, $6=$ Ovis canadensis, $7=$ Ovis dalli dalli, $8=$ Capra ibex.

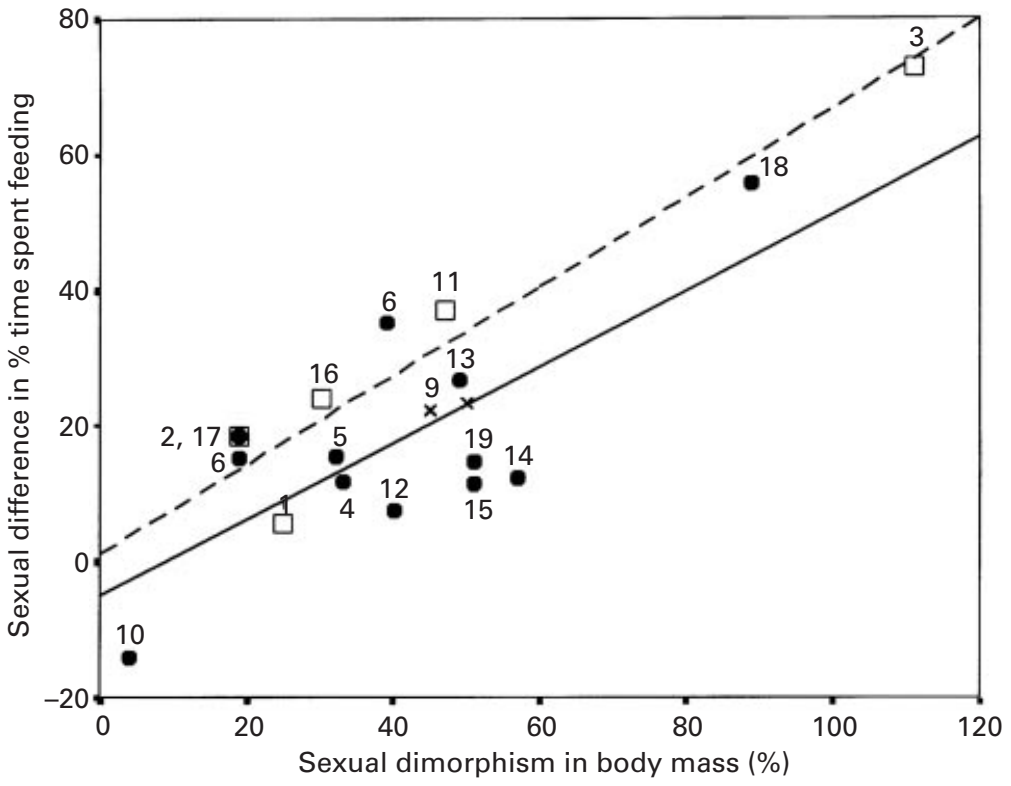

Fig. 4. Relationship between increasing sexual body mass dimorphism and sexual differences in per cent time spent feeding for bulk (filled circles, solid line), intermediate (open squares, broken line) or concentrate (x) feeders. Each point represents one species: 1=Aepyceros melampus, $2=$ Antilocapra americana, $3=$ Capra ibex, $4=$ Cervus elaphus, $5=$ Damaliscus dorcas, $6=$ Gazella thomsoni, $7=$ Giraffa camelopardalis, $8=$ Kobus ellipsiprymnus, $9=$ Litocranius walleri, $10=$ Oryx gazella, $11=$ Ovibos moschatus, $12=$ Ovis aries, $13=$ Ovis canadensis, $14=$ Ovis dalli dalli, $15=$ Ovis musimon, $16=$ Rupicapra pyrenaica parva, $17=$ Syncerus cafer, $18=$ Tragelaphus spekei selousi, $19=$ Tragelaphus strepsiceros.

$8.79 \%$ per day versus $8.50 \%$ for females (sexual dimorphism $=4 \%$ ); gerenuk (Litocranius walleri) 34.00 versus $18.70 \%$ (sexual dimorphism $=45 \%$ ); bighorn sheep 0.93 versus $1.21 \%$ (sexual dimorphism $=49 \%$ ); giraffe (Giraffa camelopardalis) 14.10 versus $16.40 \%$ (sexual dimorphism $=50 \%$ ); mouflon
(Ovis musimon) 4.70 versus $3.60 \%$ (sexual dimorphism $=51 \%$ ); ibex 1.5 versus $0.5 \%$ (sexual dimorphism $=111 \%$ ).

Hindgut fermenters were predicted to show less sexual difference in activities because they are not constrained in their time spent foraging by ru- 


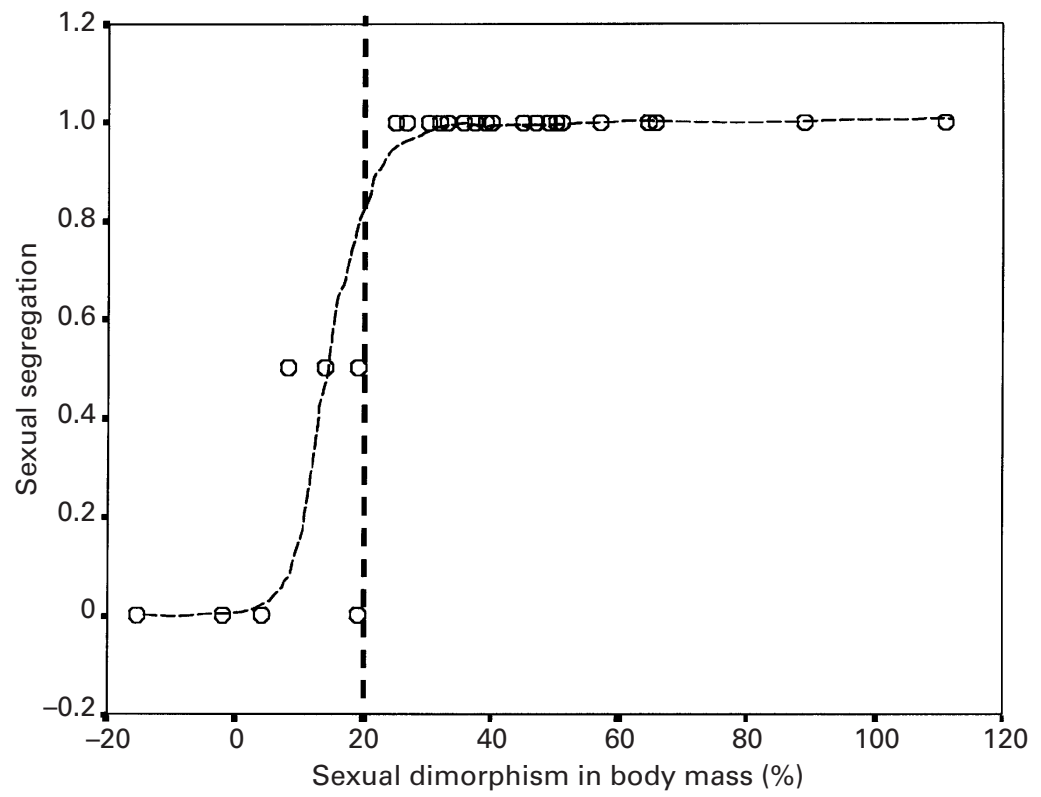

Fig. 5. Logistic regression plot of the effect of sexual body mass dimorphism on sexual segregation in social ruminants. A sexual segregation of 0 means that no segregation occurs, 0.5 represents species that sometimes live in mixed-sex groups, temporarily segregated or sometimes solitary, 1 represents segregating species. The bold dashed line represents the $20 \%$ threshold above which segregation is expected according to the assumptions of the activity budget hypothesis.

mination. Accordingly, there was only a nonsignificant trend for hindgut fermenters to increase sexual differences in time spent foraging with an increasing sexual dimorphism in body mass $\left(r^{2}=\right.$ $0.67, P=0.09, \mathcal{N}=6$; see Table 3 for sexual differences in activity and Table 2 for sexual differences in body mass).

In both intermediate feeders (five species) and bulk feeders (12 species), we found that sexual dimorphism was correlated with the difference in the per cent time males and females spent feeding (bulk feeders: $r=0.75, r^{2}=0.55, P<0.001$; intermediate feeders: $r=0.96, r^{2}=0.92, P<0.05, \mathcal{N}=5$ ); (Fig. 4). Contrary to predictions, however, intermediate feeders did not spend more time feeding for a specific body mass than bulk feeders $(Z=-1.13, P=0.26)$.

Sexual differences in body mass significantly affected segregation (ordinal logistic regression coefficient $=0.33, \quad$ S.E. of coefficient $=0.12, \quad Z=$ -2.62, $P<0.01, n_{1}=4$ non-segregating species, $n_{2}=4$ half-segregating species $(0.5)$ and $n_{3}=21$ segregating species, Fig. 5). Overall, 22 studies on ruminants showed a significant sexual difference in time spent foraging, while one did not. Impala (Aepyceros melampus) are sexually segregated but males and females have similar activity budgets (Table 3). Nevertheless, the predictions of the activity budget hypothesis were strongly supported by the results (binomial test: $n_{1}=22, n_{2}=1$, $P<0.0001$, Table 3).

\section{DISGUSSION}

Mysterud (2000) found a significant correlation between sexual size dimorphism and sexual segregation in ungulates. The bigger the difference in body sizes between males and females, the more likely they are to segregate and live in separate groups. More than 20 years have passed since the first researchers tried to solve the enigma of sexual segregation, a phenomenon common in most social ruminant species and many other mammals. Ruckstuhl \& Neuhaus (2000) suggested that a comparative analysis over a wide range of ungulate species should be carried out to find a general explanation of sexual segregation. In performing a comparative analysis of factors affecting sexual segregation for a wide variety of social ruminants and hindgut fermenters we are here able to evaluate the general validity of the three most widely accepted hypotheses on sexual segregation.

\section{(1) The predation-risk hypothesis}

The predation-risk hypothesis postulated that males and females would use different areas because of different reproductive strategies (Main \& Coblentz, 1996). Female mountain ungulates try to protect their young from predation by selecting areas that are relatively safe from predation, such as steep, inaccessible areas (e.g. bighorn sheep, Alpine ibex or 
chamois Rupicapra rupicapra). Other species hide their newborn (e.g. moose Alces alces, red deer, and other cervids), while others live in open terrain (many of the African bovids), where the best antipredator strategy probably is to form large groups. A number of studies have confirmed that females will compromise food quality over security to offspring, while males will generally be in better quality and sometimes even riskier habitat (Bergerud, Butler \& Miller, 1984; Koga \& Ono, 1994; Main \& Coblentz, 1996; Prins \& Iason, 1989; Sukumar \& Gadgil, 1988). Other studies, however, found females were using better quality habitat than males, such as in Alpine chamois where females used high-elevation meadows with the highest availability and quality of forage, while males were more concentrated in midelevation zones of lower quality and quantity of forage (Shank, 1985). White-tailed deer (Odocoileus virginianus) females also consistently had higher faecal nitrogen levels and consumed more grass and less browse than males (Beier, 1987).

Furthermore, female Dall's sheep (Ovis dalli dalli) were reported sometimes to compromise security to their offspring: in a year of low forage availability they ventured further from escape terrain to reach patches of food than in years of high forage availability (Rachlow \& Bowyer, 1998). We have shown in our analysis on the validity of the predation-risk hypothesis that approximately half of the studied species acted as predicted whereas the other half did not. Thus, predation risk alone cannot serve as a general explanation or be the driving factor for sexual segregation. We have, for example, shown that non-dimorphic female plains zebras or oryx did not segregate into safer areas, despite the greater vulnerability of their young. In addition, studies on impala, Alpine ibex, roe deer Capreolus capreolus), red deer, Thomson's gazelle (Gazella thomsoni), or giraffe, confirmed that females were using better quality habitat during at least some of the year, while moose, bison (Bison bison athabascae), bighorn sheep or African buffalo (Syncerus cafer) males sometimes used the same areas as females and ate the same quality diet (Table 3 ).

As mentioned in the introduction females could form large groups as an alternative anti-predator strategy. In these cases, we could ask why males of dimorphic species do not form mixed-sex groups with females. One explanation could be heightened competition for food in very large female groups. Prins (1989) showed that African buffalo males actually switch back and forth between female and smaller bachelor groups or become solitary pre- sumably to increase foraging efficiency. However, in so doing, they expose themselves to a much higher predation risk than when staying in female groups (Prins \& Iason, 1989). Although foraging efficiency could be a trigger to leave groups, this movement of bulls could also be interpreted by the activity budget hypothesis: males can only synchronise during a certain time after which they need to follow their optimal time budget to replenish lost energy.

\section{(2) The forage-selection hypothesis}

Sexual differences in body size likely lead to differences in digestive efficiencies (Van Soest, 1994) even within a species. These differences were hypothesised to be the main factor affecting sexual habitat segregation in ruminants, because it was suggested that females with a lower digestive efficiency should compensate by selecting highquality forage that is easily digestible, while the bigger males only require enough forage to be available (Bowyer, 1984). However, the forageselection hypothesis has been questioned on several grounds. First, there are at least three alternative strategies that females could adopt in order to compensate for their lower digestive efficiency without searching for high-quality food: to increase total intake by (1) a higher feeding rate, (2) a higher mastication rate (Gross et al., 1995), or (3) an increased fermentation rate (Bunnell \& Gillingham, 1985). Second, there is no obvious reason for males to forego high-quality forage if it is available (Gross, 1998; Main, 1998). Last, diet selection varies seasonally and diet quality may be low for both males and females during winter in temperate regions, making it hard to explain sexual segregation by habitat.

As our review of the literature showed, several researchers found females using higher quality food habitats, however, there were significantly more studies that did not find any difference between the quality of the habitat used by males or females or that found that males were actually using better quality habitat (see Table 3 ). It was also argued that female red deer on the Isle of Rum outcompeted males from preferred areas if sward height became too low for males to be profitable (Clutton-Brock, Iason \& Guinness, 1987), and males would therefore be forced to leave areas occupied by females. However, when female red deer were experimentally removed from these areas, males did not move into them even though forage was abundant Conradt, Clutton-Brock \& Thomson, 1999). We thus conclude 
that forage selection per se is unlikely to be a direct cause of sexual segregation. As was rightly suggested previously, sexual differences in diets may actually be a consequence and not a cause of sexual segregation in ruminants (Kie \& Bowyer, 1999).

\section{(3) The activity budget hypothesis}

The activity budget hypothesis proposed that males and females segregate into different groups due to incompatibilities of activity budgets. Indeed, in both red deer and bighorn sheep males and females differed in their activity budgets and members of mixed groups were less synchronised in their behaviour and the groups less stable than single sex groups (Conradt, 1998; Ruckstuhl, 1999). When synchronising, individuals in mixed-sex groups would likely compromise their optimal activity budget and potentially jeopardise each individual's energy assimilation (Ruckstuhl, 1999). Asynchrony on the other hand would lead to the dissociation of groups and increased predation risk due to lower dilution and detection (Dehn, 1990; Hamilton, 1971). The best strategy, therefore, seems to be to form same-sex or body size groups where the costs of synchrony should be low and benefits of group protection high. Such same-sex body size groups were predicted by Bon \& Campan (1996) and, for example, reported for ibex (Villaret \& Bon, 1998), mouflon (Cransac et al., 1998), bighorn sheep (Ruckstuhl \& Festa-Bianchet, 2001) and impala (Murray, 1981).

We also proposed that non-dimorphic ruminants should form mixed groups as digestive capabilities should be similar and hence also activity budgets. Non-dimorphic social species either formed monogamous pairs, such as in the dik-dik (Madoqua kirkii) or klipspringer (Oreotragus oreotragus) (Estes, 1991) or lived in mixed-sex groups, as in the pronghorn (Antilocapra americana; Byers, 1997), oryx, or some populations of roe deer (Bresinski, 1982). We have also shown that sexual differences in activity were associated with sexual segregation: with increasing sexual dimorphism in body mass sexual differences in time spent feeding and walking increased and segregation was omnipresent in species with a sexual size dimorphism above $20 \%$.

The only study where the activity budget hypothesis could not explain sexual segregation was on impala (Hudson \& White, 1985). Impala males are territorial and chase young males out of visiting female groups. These outcasts then form bachelor groups. Due to the sexual dimorphism in body mass of $25 \%$ in impalas, males and females would be expected to show a large difference in time spent feeding and to segregate, but differences in time spent feeding were in fact very small (Table 3 ). The similarity in activity budgets probably allows territorial impala males to be with females, but they may be paying a cost in terms of energy assimilation in the long run. Male impala should hence compensate energy loss by following their optimal activity budget once females leave their territory. We are unaware of any study on male impala compensatory feeding.

Polygyny has been associated with sexual size dimorphism for many species (Darwin, 1871). While a larger body size increases a male's ability to compete successfully with other males over access to oestrous females, body size confers a cost in terms of higher energy requirements (Owen-Smith, 1988). Dimorphic males should therefore only associate with females when reproducing, but form male groups outside breeding to follow optimal activity budgets.

Weckerly (1998) showed that ruminants that had a harem or tended females during the mating season were more sexually dimorphic in body size than males with monogamous mating systems or with territorial polygynous mating systems. We suggest that male ungulates of non-dimorphic species are the only ones that can energetically allow themselves to associate with females all year round, especially when they show high movement within a large home range (Owen-Smith, 1988). These species often have a non-seasonal reproduction cycle where females could come into oestrus all year round, like the oryx or the zebra (Estes, 1974). However, territorial or dominant males may succeed in evicting other males from reproductively receptive female groups and males may therefore be forced into bachelor groups outside these territories, even when they are of similar body size to the females, such as was reported in Grevy's zebra (Equus grevyi) (Groves, 1974). Male territorial behaviour may therefore explain the occurrence of bachelor groups in non-dimorphic species.

We also found that sexual differences in time spent feeding were greater between males and lactating females than between males and non-lactating females for which data were available such as in Alpine ibex, red deer, giraffe, waterbuck (Kobus ellipsiprymnus), muskoxen (Ovibos moschatus) or Dall's sheep (see Table 3 for references on activity budgets). However, both lactating and non-lactating females spent on average much more time foraging than 
males and this difference again increased with increasing sexual size dimorphism. Interestingly, females with and without young often are found together in most ungulates. These associations may either form because there are not enough nonreproducing females in a population to form predator-safe groups or non-reproducing females feed at similar levels to reproducing females to gain more fat reserves, as shown in bighorn sheep (Ruckstuhl \& Festa-Bianchet, 1998).

Overall, the activity budget hypothesis was the only one whose predictions could be confirmed in a majority of studies. It, therefore, shows clear potential as a general explanation for sexual segregation in ruminants. Ruminants chew the cud repeatedly before digestion takes place, whereas hindgut fermenters do not chew their cud and forage passes directly into the acid stomach (Van Soest, 1994). In ruminants, forage has to be masticated until it reaches a specific particle size after which it passes into the acid stomach for further digestion (Robbins, 1993). Ruminants are therefore more limited in the time spent foraging by digestive time constraints than non-ruminants. Unfortunately, there are few data available on activity budgets in hindgut fermenters. Nevertheless, there was a (nonsignificant) trend for sexual differences in activity to increase with sexual differences in body mass, just as in ruminants, but at a lower rate. It seems likely that the allometric relationship between stomach size and metabolic requirements, or stomach size and digestive efficiency will affect sexual differences in time spent foraging in both ruminant and hindgut fermenter species. The threshold level for significant sexual differences in behaviour and thus sexual segregation will however probably be higher in hindgut fermenters than the $20 \%$ difference in body mass in ruminants. Further studies, including more non-ruminant species with a wider range of sexual dimorphism, will be necessary to reach a final conclusion.

\section{GONGLUSIONS}

\section{(1) A new model to explain sexual segregation}

(1) Is there a single factor causing sexual segregation or does a combination of factors act at the same or different levels? Main (1998) pointed out that as sexual segregation is universal among polygynous ungulates it is reasonable to assume that sexual segregation has a common underlying cause.
Additive factors would then increase segregation, leading for example to spatial or habitat segregation.

(2) Conradt (1999) suggested that sexual segregation in feral Soay sheep and red deer arose because of social segregation and that relatively minor sex differences in environmental requirements could potentially lead to spatial and habitat segregation. Such in the case, we believe, with sexual differences in activity budgets. We present a hypothetical model to explain sexual segregation in ruminants by including activity differences as a central factor and predation risk and forage selection as additive factors for sexual segregation (Fig. 6).

(3) Although differences in activity budgets can lead to sexual segregation (social segregation), differences in predation risk and forage selection may additionally explain some cases where segregation by habitat occurs. On the other hand, our model also explains why some studies found sexual differences in habitat choice during one period of the year, but none at other times and why the sexes nevertheless remain sexually segregated. Kudu (Tragelaphus strepsiceros) females, for example, were found to use a variety of habitats during the wet season, while males preferentially used riverine habitat throughout the year. Females switched their preference to riverine habitat during the dry season and therefore did not show habitat segregation from males during that period (du Toit, 1995). Female and male kudu in that study possibly still differed in activity budgets but not in habitat selection. Other factors such as sexual differences in water requirements of mule deer (Odocoileus hemionus) (Bowyer, 1984) or differences in weather sensitivity in red deer (Conradt \& Guinness, 1997) have been put forward to explain some cases of habitat segregation.

(4) Predation risk certainly seems to explain some cases of habitat segregation (Jakimchuk, Ferguson \& Sopuck, 1987). Furthermore, one may consider a scenario where predation risk of different reproductive strategies lead males and females to spend different amounts of time feeding or resting. Here again, differences in activity budgets would be causing sexual segregation and not reproductive strategies directly (Fig. 6). However, sexual segregation should not occur at times when the offspring no longer depends on females for predator protection or when the quality of available forage is the same in male and female habitats (Cransac et al., 1998). We conclude that predation risk and forage selection are not primary factors causing sexual segregation.

(5) To confirm sexual differences in activity budgets as the primary cause of sexual segregation 


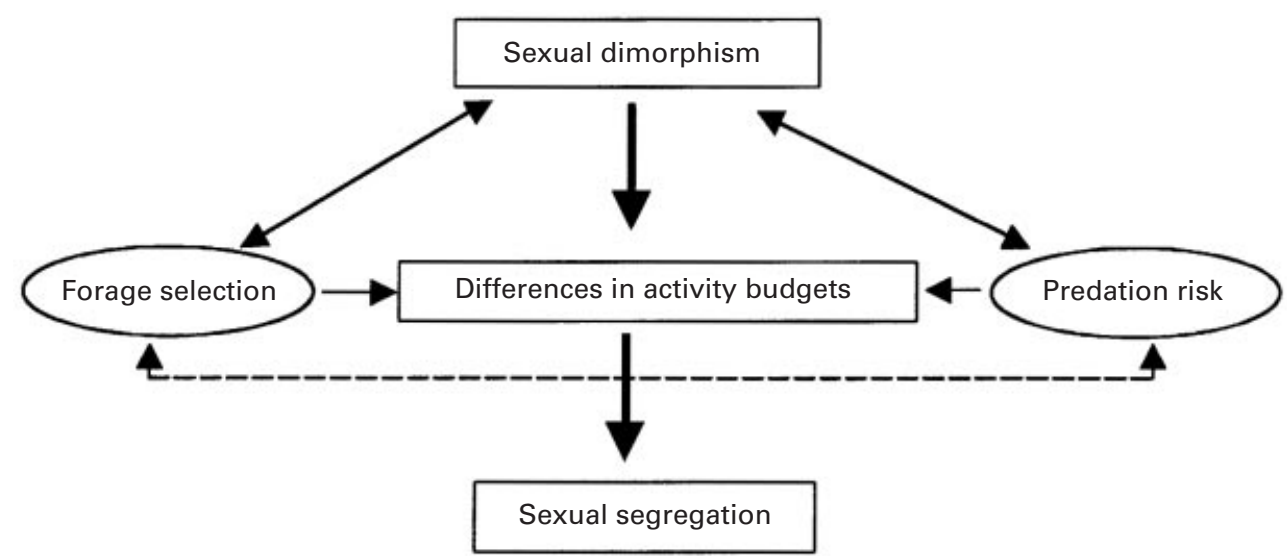

Fig. 6. Model of proposed effects of sexual body mass dimorphism on sexual differences in activity budgets and ultimately on sexual segregation. Two-way arrows indicate a correlation between different variables; one-way arrows indicate a hypothetical causal relationship.

we need to carry out research on a broad range of mammals from non-dimorphic to the most dimorphic species. Such studies seem promising, for example, in different species of whales, kangaroos or camelids, as there are taxa with species that range from non-dimorphic to very dimorphic. For all these taxa we would predict sexual differences in activity budgets to increase with increasing sexual size dimorphism up to a level where synchrony of behaviour is too costly and sexual or size segregation occurs. Segregation into similar-size groups has been amply demonstrated in schooling fish (Murphy, 1980; Pitcher, Magurran \& Edwards, 1985; Ranta, Peuhkuri \& Laurila, 1994), migrating bird flocks (Myers, 1981) and some ungulates species (Bon, Dubois \& Maublanc, 1993; Cransac et al., 1998; Murray, 1981; Ruckstuhl \& Festa-Bianchet, 2001). All of these species may segregate due to the costs of synchrony.

(6) The actual costs of synchrony for animals of different body sizes remain to be demonstrated. This requires new research in an area of behavioural ecology that has not been investigated before. Furthermore, a cost of synchrony may have to be considered as a potential cost of group living.

\section{AGKNOWLEDGEMENTS}

Funding for this study was provided by an EU Marie Curie fellowship (Improving the Human Research Potential and Socio-Economic Knowledge Base) granted through the Swiss National Science Foundation (19992000), by an NSERC postdoctoral fellowship (20012003), a 2000 Canada-UK Millennium Research Award, and by a Swiss National Science Foundation travel grant to K.E.R.A Challenge Grant in Biodiversity financed through the Alberta Department of Environmental
Protection, Fish and Wildlife Trust Fund and the University of Alberta, Department of Biological Sciences, the Alberta Sports, Recreation Parks and Wildlife Fund and NSERC and FCAR grants funded the study on bighorn sheep. K.E.R. is indebted to Marco FestaBianchet, Jon Jorgenson, Ian Ross and all field assistants for their invaluable help in various aspects of the bighorn sheep study. We are also grateful to the Office Nationale de la Chasse and in particular Michel Catusse, Jacques Michallet and Carole Toïgo for letting us study their ibex population. Thanks to the Etosha National Park and the Ministry of Environment Windhoek, and in particular Holger Kohlberg, Johan Le Roux and Peter Erb for accommodation, logistics and permits to study oryx and zebra. We especially thank Norman Owen-Smith, Marco Festa-Bianchet, Tim Clutton-Brock and two anonymous referees for their insights and helpful comments on earlier drafts of this manuscript. Thanks to Paul Harvey and Annette Mahon for advice on ungulate phylogenies.

\section{REFERENGES}

Aвouheif, E. (1999). A method for testing the assumption of phylogenetic independence in comparative data. Evolutionary Ecology Research 1, 895-909.

Altmann, J. (1974). Observational study of behavior: sampling methods. Behaviour 49, 227-267.

Beier, P. (1987). Sex differences in quality of white-tailed deer diets. Journal of Mammalogy 68, 323-329.

Bergerud, A. T., Butler, H. E. \& Miller, D. R. (1984). Antipredator tactics of calving caribou: dispersion in mountains. Canadian Fournal of Zoology 62, 1566-1575.

Berry, H. H. (1980). Behavioural and eco-physiological studies on wildebeest (Connochaetes taurinus) at the Etosha National Park Ph.D. thesis. University of Cape Town.

Bleich, V. C., Bowyer, R. T. \& Wehausen, J. D. (1997). Sexual segregation in mountain sheep: resources or predation? Wildlife Monographs 134, 1-50. 
Bon, R. \& Campan, R. (1996). Unexplained sexual segregation in polygamous ungulates: a defence of an ontogenetic approach. Behavioural Processes 38, 131-154.

Bon, R., Dubois, M. \& Maublanc, M. L. (1993). Does age influence between-rams companionship in mouflon (Ovis gmelini)? Revue Écologie de Terre et Vie 48, 57-64.

Bosch, P. C. \& Svensen, G. E. (1987). Behavior of male and female vicuna (Vicuna vicuna Molina 1782). Fournal of Mammalogy 68, 425-429.

Bowyer, R. T. (1984). Sexual segregation in southern mule deer. Journal of Mammalogy 65, 410-417.

Bresinski, W. (1982). Grouping tendencies in roe deer under agrocenosis conditions. Acta Theriologica 27, 327-447.

Bunnell, F. L. \& Gillingham, M. P. (1985). Foraging behavior: dynamics of dining out. In Bioenergetics of wild herbivores (eds. R. J. Hudson and R. G. White), pp. 53-75. CRG Press, Inc., Boca Raton.

Byers, J. A. (1997). American pronghorn. Social adaptations and the ghosts of predators past. University of Chicago Press, Chicago.

Clutton-Brock, T. H., Guinness, F. E. \& Albon, S. D. (1982). Red deer. Behavior and ecology of two sexes. University of Chicago Press, Chicago.

Clutton-Brock, T. H., Iason, G. R. \& Guinness, F. E. (1987). Sexual segregation and density-related changes in habitat use in male and female red deer (Cervus elaphus). Fournal of Zoology London 211, 275-289.

Conradt, L. (1998). Could asynchrony in activity between the sexes cause intersexual social segregation in ruminant? Proceedings of the Royal Society London, Series B 265, 1359-1363.

Conradt, L. (1999). Social segregation is not a consequence of habitat segregation in red deer and feral soay sheep. Animal Behaviour 57, 1151-1157.

Conradt, L., Glutton-Brock, T. H. \& Thomson, D. (1999). Habitat segregation in ungulates: are males forced into suboptimal habitats through indirect competition by females? Oecologia 119, 367-377.

Conradt, L. \& Guinness, F. (1997). Habitat segregation and weather sensitivity in red deer (Cervus elaphus L.). Advances in Ethology, Supplements to Ethology, 172.

Cough, G. \& Hassam, A. G. (1970). A quantitative study of the daily activity of the warthog in the Queen Elisabeth National Park, Uganda. East African Wildlife Fournal 8, 19-24.

Cransac, N., Gerard, J.-F., Maublanc, M.-L. \& Pépin, D. (1998). An example of segregation between age and sex classes only weakly related to habitat use in mouflon sheep (Ovis gmelini). Fournal of Zoology London 244, 371-378.

Cransac, N. \& Hewison, A. J. M. (1997). Seasonal use and selection of habitat by mouflon (Ovis gmelini): comparison of the sexes. Behavioural Processes 41, 57-67.

DARwin, G. (1871). The descent of man, and selection in relation to sex. Appleton, New York.

Denn, M. M. (1990). Vigilance for predators: detection and dilution effects. Behavioral Ecology and Sociobiology 26, 337-342.

Demment, M. W. (1982). The scaling of ruminoreticulum size with body weight in East African ungulates. African Fournal of Ecology 20, 43-47.

Demment, M. W. \& Van Soest, P.J. (1985). A nutritional explanation for body-size patterns of ruminant and nonruminant herbivores. American Naturalist 125, 641-672.

Du Toit, J. T. (1995). Sexual segregation in kudu: sex differences in competitive ability, predation risk or nutritional needs? South African Fournal of Wildlife Research 25, 127-132.

Dunbar, R. I. M. (1979). Energetics, thermoregulation and the behavioural ecology of klipspringer. African fournal of Ecology 17, 217-230.

Duncan, P. (1980). Time-budgets of Camargue horses. II. Time-budgets of adult horses and weaned sub-adults. $B e$ haviour 72, 26-49.

Duncan, P., Foose, T. J., Gordon, I. J., Gakahu, G. G. \& Loyd, M. (1990). Comparative nutrient extraction from forages by grazing bovids and equids: a test of the nutritional model of equid-bovid competition and coexistence. Oecologia 84, 411-418.

Estes, R. D. (1974). Social organization of the African bovidae. IUCN, Morges, Switzerland.

Estes, R. D. (1991). The behavior guide to African mammals. Including hoofed mammals, carnivores, primates. University of California Press, Berkley.

Felsenstein, J. (1985). Phylogenies and the comparative method. American Naturalist 125, 1-15.

Festa-Bianchet, M. (1988). Seasonal range selection in bighorn sheep: conflicts between forage quality, forage quantity, and predator avoidance. Oecolgia 75, 580-586.

FrID, A. (1999). Huemul (Hippocamelus bisulcus) sociality at a periglacial site: sexual aggregation and habitat effects on group size. Canadian Fournal of Zoology 77, 1083-1091.

Games, I. (1983). Observations of the Sitatunga Tragelaphus spekei selousi in the Okavango Delta of Botswana. Biological Conservation 27, 157-170.

Ginnett, T. F. \& Demment, M. W. (1997). Sex differences in giraffe foraging behavior at two spatial scales. Oecologia 110, 291-300.

Gross, J. E. (1998). Sexual segregation in ungulates: a comment. Fournal of Mammalogy 79, 1404-1409.

Gross, J. E., Demment, M. W., Alkon, P. U. \& Kotzman, M. (1995). Feeding and chewing behaviours of Nubian ibex: compensation for sex-related differences in body size. Functional Ecology 9, 385-393.

Groves, C. P. (1974). Horses, asses and zebras in the wild. David \& Charles, London.

Hamilton, W. D. (1971). Geometry for the selfish herd. Fournal of Theoretical Biology 31, 295-311.

Harvey, P. \& Rambaut, A. (2000). Comparative analyses for adaptive radiation. Philosophical Transactions of the Royal Society London, Series B 355, 1599-1605.

Harvey, P. H. \& Mace, G. M. (1982). Comparisons between taxa and adaptive trends: problems of methodology. In Current problems in sociobiology (ed. K. S. C. S. Group), pp. 394. Cambridge University Press, Cambridge.

Harvey, P. H. \& Pagel, M. D. (1998). The comparative method in evolutionary biology. Oxford University Press, Oxford.

Harvey, P. H., Read, A. F. \& Nee, S. (1995). Why ecologists need to be phylogenetically challenged. Fournal of Ecology 83, 535-536.

Hofmann, R. R. (1989). Evolutionary steps of ecophysiological adaptation and diversification of ruminants: a comparative view of their digestive system. Oecologia 78, 443-457.

Hudson, R.J. \& White, R. G. (1985). Bioenergetics of wild herbivores. CRC Press Inc., Boca Raton.

Jakimchuk, R. D., Ferguson, S. H. \& Sopuck, L. G. (1987). Differential habitat use and sexual segregation in the Central Arctic caribou herd. Canadian Fournal of Zoology 65, 534-541.

Kie, J. G. \& Bowyer, R. T. (1999). Sexual segregation in white-tailed deer: density-dependent changes in use of space, habitat selection, and dietary niche. Fournal of Mammalogy 80, 1004-1020. 
Kingdon, J. (1997). The Kingdon field guide to African mammals. Academic Press Limited, London.

Koga, T. \& Ono, Y. (1994). Sexual differences in foraging behavior of sika deer, Cervus nippon. Fournal of Mammalogy 75 (1), 129-135.

Larter, N. G. \& Gates, C. C. (1991). Diet and habitat selection of wood bison in relation to seasonal changes in forage quantity and quality. Canadian Fournal of Zoology 69, 2677-2685

Lefebre-Smuts, G. (1974). Growth, reproduction and population characteristics of Burchell's zebra (Equus burchelli antiquorum, H. Smith, 1841). Ph.D. thesis, Pretoria.

Lenarz, M. S. (1985). Lack of diet segregation between sexes and age groups in feral horses. Canadian Fournal of Zoology 63, 2583-2585.

Loison, A., Gaillard, J.-M., Pélabon, G. \& Yoccoz, N. G. (1999). What factors shape sexual size dimorphism in ungulates? Evolutionary Ecology Research 1, 611-633.

Leuthold, B. M. \& Leuthold, W. (1978). Daytime activity patterns of gerenuk and giraffe in Tsavo National Park, Kenya. East African Wildlife fournal 16, 231-243.

Main, M. B. (1998). Sexual segregation in ungulates: a reply. Fournal of Mammalogy 79, 1410-1415.

Main, M. B. \& Coblentz, B. E. (1990). Sexual segregation among ungulates: a critique. Wildlife Society Bulletin 18, 204-210.

Main, M. B. \& Coblentz, B. E. (1996). Sexual segregation in Rocky Mountain mule deer. Fournal of Wildlife Management 60, 497-507.

Main, M. B., Weckerly, F. W. \& Bleich, V. C. (1996). Sexual segregation in ungulates: new directions for research. Fournal of Mammalogy 77, 449-461.

Manser, M. B. \& Brotherton, P. N. M. (1995). Environmental constraints on the foraging behaviour of a dwarf antelope (Madoqua kirkii). Oecologia 102, 404-412.

MaCullough, D. R. (1979). The George reserve deer herd. University of Michigan Press, Ann Arbor.

Miquelle, D. G., Peek, J. M. \& Van Ballenberghe, V. (1992). Sexual segregation in Alaskan moose. Wildlife Monographs 122, 1-57.

Moncorps, S., Boussès, P., Réale, D. \& Ghapuis, J.-L. (1997). Diurnal time budget of the mouflon (Ovis musimon) on the Kerguelen archipelago: influence of food resources, age, and sex. Canadian Fournal of Zoology 75, 1828-1834.

Murphy, G. I. (1980). Schooling and the Ecology and Management of Marine Fish. In Physiological and Behavioral Manipulation of Food Fish as Production and Management Tools (eds. J. E. Bardach, J. J. Magnuson, R. C. May and J. M. Reinhart), pp. 400-412. IOLARM, Manila.

Murray, M. G. (1981). Structure of association in impala, Aepyceros melampus. Behavioral Ecology and Sociobiology 9, 23-33.

Myers, J. P. (1981). A test of three hypotheses for latitudinal segregation of the sexes in wintering birds. Canadian fournal of Zoology 59, 1527-1534.

Mysterud, A. (2000). The relationship between ecological segregation and sexual body size dimorphism in large herbivores. Oecologia 124, 40-54.

Oakes, E. J., Harmsen, R. \& Eberl, C. (1992). Sex, age, and seasonal differences in the diets and activity budgets of muskoxen (Ovibos moschatus). Canadian Fournal of Zoology 70, 605-616.

Owen-Smith, R. N. (1988). Megaherbivores. The influence of very large body size on ecology. Cambridge University Press, London.
Owen-Smith, N. (1998). How high ambient temperature affects the daily activity and foraging time of a subtropical ungulate, the greater kudu (Tragelaphus strepsiceros). Fournal of Zoology London 246, 183-192.

PAgel, M. D. (1992). A method for the analysis of comparative data. Fournal of Theoretical Biology 156, 431-442.

Pellew, R. A. (1984). The feeding ecology of a selective browser, the giraffe (Giraffa camelopardalis tippelskirchi). Fournal of Zoology London 202, 57-81.

Pèrez-Barberia, F.J. \& Gordon, I. J. (1999). Body size dimorphism and sexual segregation in polygynous ungulates: an experimental test with Soay sheep. Oecologia 120, 258-267.

Pérez-Barberia, F. J. \& Gordon, I. J. (2000). Differences in body mass and oral morphology between the sexes in the Artiodactyla: evolutionary relationships with sexual segregation. Evolution and Ecology Research 2, 667-684.

Pérez-Barberia, F.J., Olivan, M., Osoro, K. \& Nores, C. (1997). Sex, seasonal and spatial differences in the diet of Cantabrian chamois Rupicapra pyrenaica parva. Acta Theriologica 42, 37-46.

Pitcher, T.J., Magurran, A. E. \& Edwards, J. I. (1985). Schooling mackerel and herring choose neighbours of similar size. Marine Biology 86, 319-322.

Prins, H. H. T. (1989). Condition changes and choice of social environment in African Buffalo bulls. Behaviour 108, 297-324.

Prins, H. H. T. \& Iason, G. R. (1989). Dangerous lions and nonchalant buffalo. Behaviour 108, 262-296.

Prins, H. H. T. (1996). Ecology and behaviour of the African buffalo. Social inequality and decision making, 1st edition. Chapman \& Hall, London.

Rachlow, J. L. \& Bowyer, T. R. (1998). Habitat selection by Dall's sheep (Ovis dalli) : maternal trade-offs. Fournal of Zoology London 245, 457-465.

Ranta, E., Peuhkuri, N. \& Laurila, A. (1994). A theoretical exploration of antipredatory and foraging factors promoting phenotype-assorted fish schools. Ecoscience 1, 99-106.

Rees, M. (1995). EG-PC comparative analyses? fournal of Ecology 83, 891-893.

Robbins, C. T. (1993). Wildlife feeding and nutrition, Second edition. Academic Press, Harcourt Brace Jovanovich, New York.

Ruckstuhl, K. E. (1998). Foraging behaviour and sexual segregation in bighorn sheep. Animal Behaviour 56, 99-106.

Ruckstuhl, K. E. (1999). To synchronise or not to synchronise: a dilemma in young bighorn males? Behaviour 136, 805-818.

Rugkstuhl, K. E. \& Festa-Bianchet, M. (1998). Do reproductive status and lamb gender affect the foraging behavior of bighorn ewes? Ethology 104, 941-954.

Rugkstuhl, K. E. \& Festa-Bianchet, M. (2001). Group choice by subadult male bighorn sheep: trade-offs between foraging efficiency and predator avoidance. Ethology 107, 161-172.

Ruckstuhl, K. E. \& Neuhaus, P. (2000). Sexual segregation in ungulates: a new approach. Behaviour 137, 361-377.

Seip, D. R. \& Bunnell, F. L. (1985). Foraging behaviour and food habits of Stone's sheep. Canadian Fournal of Zoology 63, 1638-1646.

Shank, C. C. (1985). Inter- and intra sexual segregation of chamois (Rupicapra rupicapra) by altitude and habitat during summer. Zeitschrift für Sāugetierkunde 50, 117-125.

Short, H. L. (1963). Rumen fermentations and energy relationships in white-tailed deer. Fournal of Wildlife Management 27, 184-195.

Sokal, R. R. \& Rohlf, F.J. (1995). Biometry, Third edition. W. H. Freeman and Company, New York. 
Spinage, C. A. (1968). A quantitative study on the daily activity of the Uganda Defassa waterbuck. East African Wildlife Fournal 6, 89-93.

Sukumar, R. \& Gadgil, M. (1988). Male-female differences in foraging on crops by Asian elephants. Animal Behaviour 36, 1233-1235.

Van Soest, P. J. (1994). Nutritional ecology of the ruminant, Second edition. Cornell University Press, Ithaca, New York.

Van Soest, P.J. (1966). Allometry and ecology of feeding behavior and digestive capacity in herbivores. Zoo Biology 15, 455-479.

Van Wieren, S. E. (1991). Factors limiting food intake in ruminants and non ruminants in the temperate zone. In Ongulés/Ungulates, vol. 1. Ongulés/Ungulates, pp. 139-145. Toulouse, France

Villaret, J. C. \& Bon, R. (1998). Sociality and relationships in Alpine ibex (Capra ibex). Revue Écologie de Terre et Vie 53, 153-170.
Villaret, J. G., Bon, R. \& Rivet, A. (1997). Sexual segregation of habitat by the alpine ibex in the French Alps. Fournal of Mammalogy 78, 1273-1281.

Vrahimis, S. \& Kok, O. B. (1993). Daily activity of black wildebeest in a semi-arid environment. African fournal of Ecology 31, 328-336.

WALther, F. R. (1973). Round-the-clock activity of Thomson's gazelle (Gazella thomsoni Guenther 1884) in Serengeti National Park. Zeitschrift für Tierpsychologie 32, 75-105.

Wegkerly, F. W. (1998). Sexual-size dimorphism: influence of mass and mating systems in the most dimorphic mammals. Fournal of Mammalogy 79, 33-52.

Westoby, M., Leishman, M. \& Lord, J. (1995a). Further remarks on phylogenetic correction. Fournal of Ecology 83, $727-729$.

Westoby, M., Leishman, M. R. \& Lord, J. M. (1995b). On misinterpreting the 'phylogenetic correction'. Fournal of Ecology 83, 531-534. 